Revue des patrimoines

\title{
Entre pratique inaugurale et trésor mémoriel : étude du contenu de la statue de Henri IV de 1818
}

Département de l'action culturelle et éducative et Archives nationales

\section{(2) OpenEdition}

Journals

Édition électronique

URL : http://journals.openedition.org/insitu/7011

DOI : 10.4000/insitu.7011

ISSN : 1630-7305

Éditeur

Ministère de la culture

Référence électronique

Département de l'action culturelle et éducative et Archives nationales, « Entre pratique inaugurale et trésor mémoriel : étude du contenu de la statue de Henri IV de 1818 », In Situ [En ligne], 14 | 2010, mis en ligne le 10 avril 2012, consulté le 01 mai 2019. URL : http://journals.openedition.org/insitu/7011 ; DOI : 10.4000/insitu.7011

Ce document a été généré automatiquement le 1 mai 2019.

\section{(†)

In Situ Revues des patrimoines est mis à disposition selon les termes de la licence Creative Commons Attribution - Pas d'Utilisation Commerciale - Pas de Modification 4.0 International. 


\title{
Entre pratique inaugurale et trésor mémoriel : étude du contenu de la statue de Henri IV de 1818
}

\author{
Département de l'action culturelle et éducative et Archives nationales
}

1 La pratique qui consiste à placer dans un monument public une charte de fondation retraçant dans quelles conditions il fut érigé, quels furent les commanditaires, etc. est acquise bien avant l'érection du bronze de Lemot en 1818. Le document retrouvé en $1792^{1}$ dans le premier groupe équestre réalisé par Jean de Bologne et érigé au Pont-Neuf en 1614 l'illustre déjà. Cependant, d'une inauguration à l'autre, la nature des pièces que l'on enferme dans la statue d'Henri IV change. Ou, plus exactement, d'une simple pièce commémorative (charte, médaille), le contenu évolue, s'enrichit, pour former un ensemble dont les caractéristiques matérielles et le contenu intellectuel permettent de penser qu'il fut constitué comme une sorte de "trésor », voire de reliquaire spirituel, en mémoire du roi. Ainsi la statue équestre, en même temps qu'elle s'offre manifestement comme un symbole de l'autorité monarchique restaurée, est également investie d'une fonction de réceptacle de la mémoire collective, et ce faisant d'organe possible de réconciliation de la nation.

\section{Les actes enfermés dans les monuments publics : une pratique ancienne}

2 L'acte de 1614 a été retrouvé en 1792 enfermé dans un tuyau de plomb soigneusement cacheté : ce conditionnement témoigne d'une volonté de conserver, de préserver à travers le temps la mémoire de l'événement décrit dans le texte.

De manière générale, la pose de la première pierre d'un édifice s'accompagne souvent de l'insertion d'un document écrit au cœur des fondations, pour en préciser l'origine, les commanditaires, voire le maître d'œuvre. 


\section{La pratique médiévale de la pierre de fondation}

4 Durant les derniers siècles du Moyen Âge, et au-delà, est gravée dans la pierre même et visible dans les partie apparentes de l'appareil une inscription détaillant les conditions de la fondation: c'est le cas dans les édifices religieux, où une pierre du chœur, voire d'une chapelle ajoutée a posteriori porte souvent mention de la date d'édification du bâtiment, et révèle l'identité des éventuels donateurs et de l'architecte.

5 À cet instrument de commémoration que constitue la pierre de fondation, document gravé à même l'édifice en quelque sorte, s'ajoute, en contexte ecclésiastique, l'usage fréquemment attesté d'enfermer dans la maçonnerie un calice, de verre ou de bois, ayant servi à la célébration de l'eucharistie. Ce geste participe de la consécration de l'édifice, de sa vocation sainte, le calice ayant fonction de signe, de signature même ${ }^{2}$ chargée d'effectuer la mutation de l'édifice matériel en édifice spirituel. Par-delà les conditions objectives, matérielles, de la réalisation du bâtiment, c'est en effet son caractère sacral que vise à manifester, même s'il est caché, le calice enfermé.

\section{Médailles, chartes}

6 L'inscription commémorative portée sur la pierre de fondation d'un édifice est relayée voire concurrencée à l'époque moderne par le scellement au sein de la maçonnerie d'une boîte contenant une médaille frappée pour l'occasion, ou d'un document faisant état des conditions de la réalisation et/ou de l'inauguration de l'ouvrage. Si, par exemple, les piles du pont Notre-Dame, élevé dans les premières années du XVI ${ }^{e}$ siècle, portaient mention de la date de son érection, celles du Pont-Neuf, un siècle plus tard, contiennent une médaille commémorative.

\section{L'exemple du premier cavalier du Pont-Neuf}

7 L'effigie équestre d'Henri IV installée sur le Pont-Neuf en 1614 est le premier monument sculpté utilisé en France pour scander l'espace urbain, le premier à s'y imposer à l'instar d'un édifice public. Dans ces conditions, il n'est guère étonnant que les commanditaires aient choisi de placer une charte de fondation dans la statue. Comme la pierre de fondation gravée, héritage médiéval, celle-ci fait la part autant aux artistes ayant réalisé le modèle qu'au maître d'ouvrage. Elle s'étend également, détail intéressant, sur les étapes successives de la conception et de la réalisation du groupe, qui reprend un modèle de cheval initialement conçu par Jean de Bologne pour la statue de Ferdinand de Médicis.

«A la très glorieuse et immortelle mémoire du très auguste et invincible Henry le Grand quatriesme du nom Roi de France et de Navarre, le sérénissime Grand-Duc de Thoscane Ferdinend <meü> de <zelle> ( ?) vers la postérité, feist faire et jecter en bronze, par l'excellent sculpteur Jehan de Boulogne, ceste efigie, représentant sa Majesté très chrestienne à cheval : que le sérénissime Grand-Duc Cosme second du nom feist achever d'élaborer par le sieur Pietro Taca son sculpteur et l'envoya en très digne présent soubz la conduite du chevalier Pescholin agent de son altesse sérénissime, et d'Anthonio Guide, ingénieur, à la très chrestienne et très auguste Marie de Médicis royne regente en France après le décès de ce grans roi soubz le règne du très auguste Louis treiziesme du nom Roi de France et Navarre.... $»^{3}$ 
9 La charte de fondation telle qu'elle se décline à l'occasion de l'inauguration de ce monument public d'un genre nouveau qu'est la statue équestre accorde une attention toute particulière aux artistes et à leur travail. Il s'agit là d'un élément important, auquel du moins la statue de 1818 et les objets qui s'y trouvent font délibérément écho, puisque, parmi eux, on compte une ampliation du procès-verbal d'inauguration de la statue de Jean de Bologne, en 1614.

10 Le fait même d'avoir inséré dans la première des boîtes contenues dans le cheval de 1818 une copie de ce parchemin, découvert en 1792, et déposé dès lors aux Archives nationales, est pour le moins significatif: le nouveau bronze vient ainsi abolir la destruction du premier, s'y substituant le plus adéquatement possible. Les archives du secrétariat général et des sections des Archives royales font mention, pour le mois de juillet 1818, du travail de copie réalisé pour reproduire l'acte original en vue de l'inauguration de la nouvelle statue :

«Etat des travaux qui ont été faits aux dites Archives durant le mois de juillet 1818.

...

Section législative. (...)

Petitpierre (...) Pendant ce mois Mr Petitpierre a fait six recherches qui ont donné lieu à autant d'expéditions d'ensemble, 15 rôles, plus 3 copies d'états d'appointement, ainsi que la copie du P. v(erb)al d'inauguration de la statue de Henry IV... $»^{4}$

De même qu'il est demandé à Lemot d'approcher le plus possible l'aspect de la statue de Jean de Bologne, l'ampliation de la charte de fondation de 1614 réalisée en 1818 est voulue comme une copie, et reproduit de fait les caractéristiques matérielles (parchemin, graphie) du document ancien.

\section{L'ensemble découvert dans la statue de 1818}

12 En 1814, une effigie provisoire était installée au Pont-Neuf. Sous le groupe équestre avaient été placés un certain nombre d'objets commémoratifs, que l'on retira de la statue provisoire au moment de l'inauguration du piédestal définitif par Louis XVIII, le 28 octobre 1817.

13 «Ce jour d'hui seize mai mil huit cent dix-huit, huit heures du matin, nous Jean-Baptiste Le Père, architecte chargé de l'exécution du monument de la statue équestre de Henry IV, en vertu des instructions données par $\mathrm{S}<0 n>\mathrm{E}<\mathrm{xcellence>} \mathrm{le} \mathrm{ministre} \mathrm{de} \mathrm{l'Intérieur,}$ lesquelles nous ont été transmises par $\mathrm{M}$. le chevalier Bruyère Directeur des travaux publiés, de déposer la première pierre du piédestal de la dite statue, laquelle pierre a été posée par sa Majesté le vingt-huit octobre dernier, et d'enlever la boîte contenant sept pièces de monnaie dont deux d'or et cinq d'argent au (...) de mil huit cent dix-sept, ainsi que le portrait en cristal de sa Majesté Louis XVIII, et une plaque en bronze dorée d'or moulé portant inscription, nous avons en présence de M. le marquis de Marbois président du comité de souscription et de M. Duchosel conseiller de Préfesture, délégué par M. le Préfet du Département de la Seine, procédé à la dépose de la première pierre ci-dessus désignée et avons retiré la boîte contenant les objets ci-devant détaillés, laquelle a été remise à $\mathrm{M}$. le Conseiller de Préfecture délégué pour être, après avoir été entourée de deux bandes croisée sur lesquelles a été apposé les cachets du Président du Comité, par lui rendue lors du replacement de la première pierre du piédestal. $»^{5}$ 

cheval ont été trouvés, cachés dans la tête du cavalier, trois petits étuis dont ne fait pas mention l'inventaire des pièces introduites dans la statue, tel qu'il a été transcrit après son extraction de la boîte $n^{\circ} 1$. Du premier de ces trois étuis, un cylindre en bois de petite taille, a été extrait un morceau de parchemin roulé qui porte la liste et les signatures des ciseleurs et fondeurs ayant réalisé la statue : la mise à plat de ce document a été réalisée par l'atelier de restauration des Archives nationales. Dans la plus petite des deux autres boîtes, toutes deux en étain, un autre morceau de papier ou de parchemin n'a pu être également déroulé, attendu la fragilité de l'objet. Le plus gros des deux étuis de plomb, qui porte sur son couvercle le nom Mesnel gravé, renferme, plaqué sur l'une de ses parois intérieures par un matériau ressemblant à de la colle animale, un petit morceau de papier, de parchemin et/ou de tissu, sur lequel seules des analyses scientifiques poussées seraient à même de fournir quelque information. L'intérêt de cette découverte tient à la mention qui y est faite de Mesnel, fondeur de la statue. Aurait-il, à l'insu, bien sûr, des commanditaires de l'œuvre, caché ces boîtes dans la tête du cavalier? Qu'aurait-il dissimulé sous la couche de colle du réceptacle qui porte son nom?

\section{premier article de la sous-cote, puis le premier document sorti, etc.}

19 
Figure 1

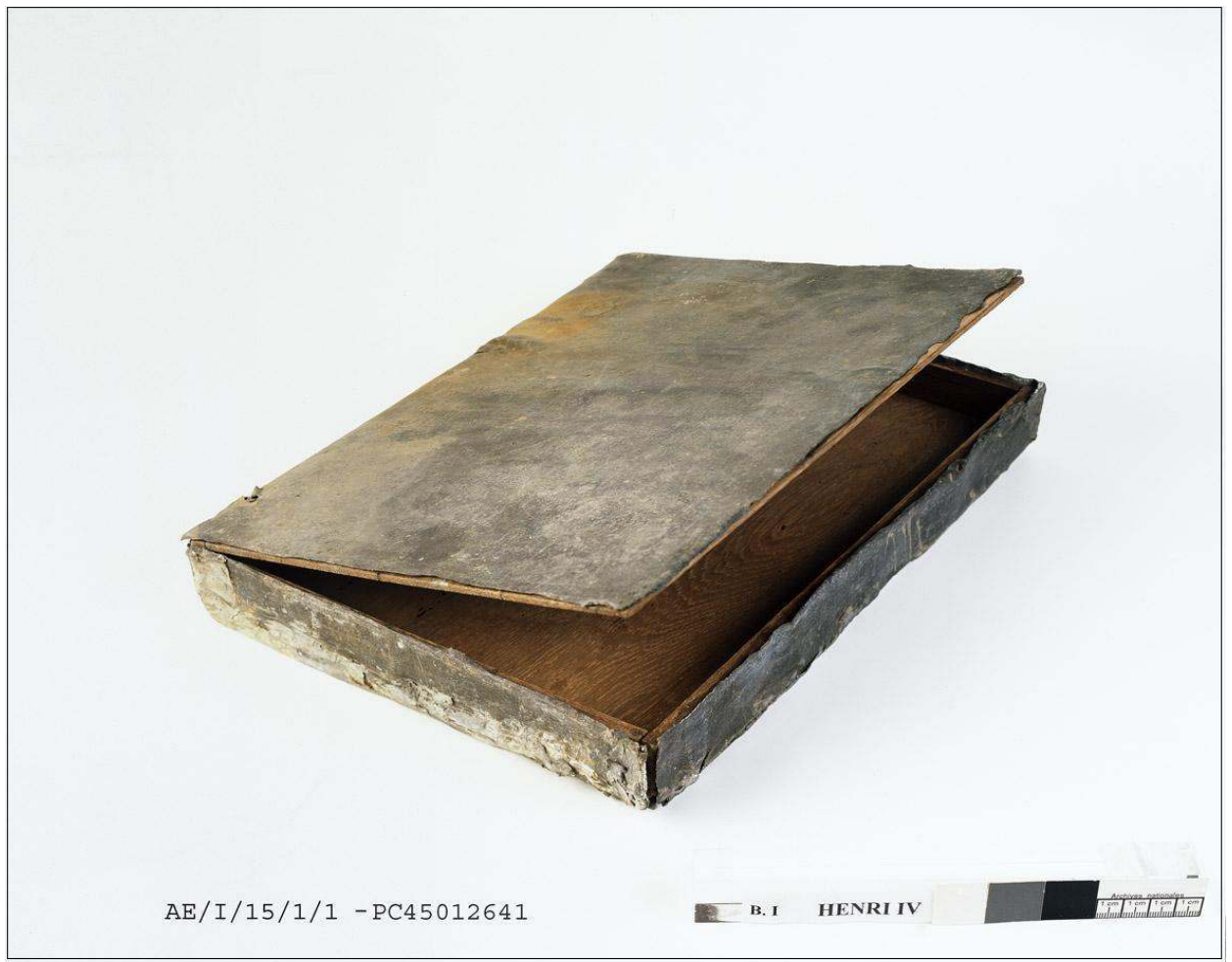

Boîte $n^{\circ} 1$

Phot. Département de la conservation. (C) Archives nationales, Paris

Boîte $1(\mathrm{AE} / \mathrm{I} / 15 \mathrm{bis} / 1 / 1)^{6}$

Document 1 (AE/I/15bis/1/3)

Ampliation sur parchemin du procès verbal de 1614

Parchemin

H. $60 \mathrm{~cm} \times$ L. $42,2 \mathrm{~cm}$ 
Figure 2

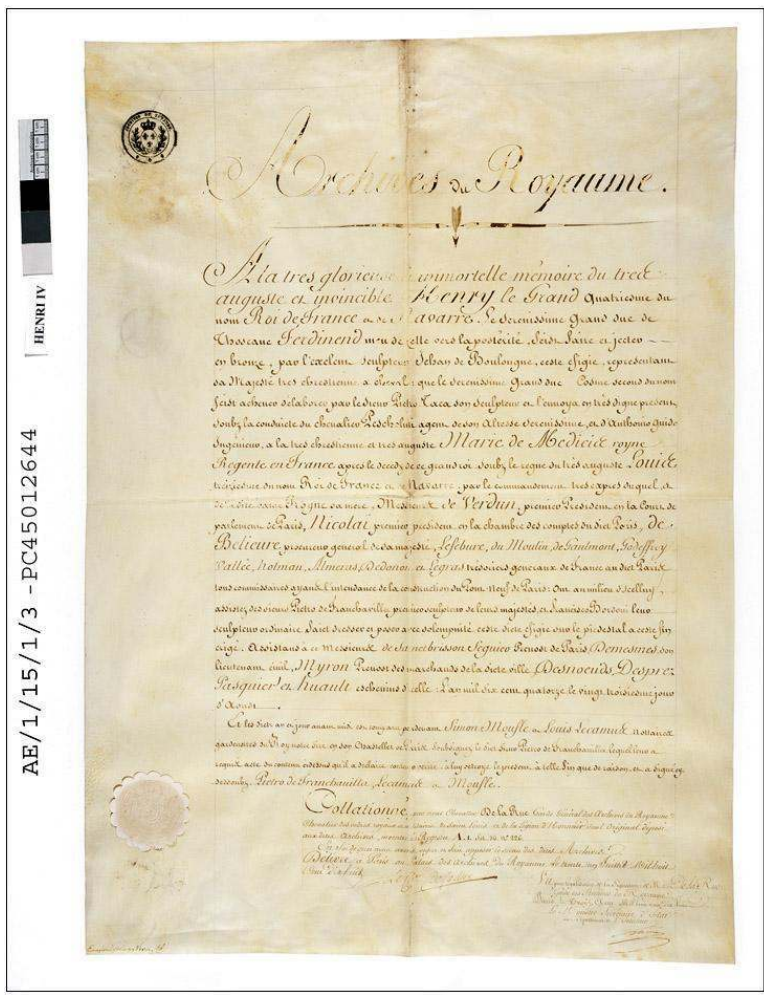

Ampliation du procès-verbal d'inauguration de 1614

Phot. Département de la conservation. ( ) Archives nationales, Paris

Document 2 (AE/I/15bis/1/6)

Liste des membres du Comité de souscription (sans date)

Parchemin sur carton

H. 34,5 x L. 23,5 x E. $1 \mathrm{~cm}$

«MM 


\begin{tabular}{|c|c|c|}
\hline Avaray & Lo Duod' & Pair de France \\
\hline Barthilemy & Le Marquis & Pair de France \\
\hline Beatused & Le Cardinal Das & Pair de Franoe \\
\hline Caraman & Le Comte Marquis & Marichal de eamp \\
\hline Chatrol do Volvic & Le Comte do & Prúfet de la Scino \\
\hline Dufourny & de IJPeadémie des Sciknoes & Memibre de 1'Institut \\
\hline Harcourt & Le Marquie of & Pair de Franose \\
\hline Levis & Le Due de & Pair de Franos \\
\hline Mintiós & Lo Marquis do & Pair do Frances \\
\hline Perighoth & & membre du Couseil genéral du département \\
\hline Quatremtre de Quincy & de T'Aeadtemie des weienes & Membre de 1 Tnstitut \\
\hline Seguier & Le Baron de & Pair de Franee \\
\hline Suand & & Secrútníre perpétuel do l'Académio franyaise \\
\hline Vahiny & Le Marquas de & Lieutitant géntral \\
\hline Lemice & Statuaire & Membere de 17notitut \\
\hline Denis & Trésoricr du Comité & Doyen des notaires de Paris \\
\hline Pisrret & Secrétnire du osenité & Référendaire a la sour des somptes \\
\hline
\end{tabular}

Figure 3

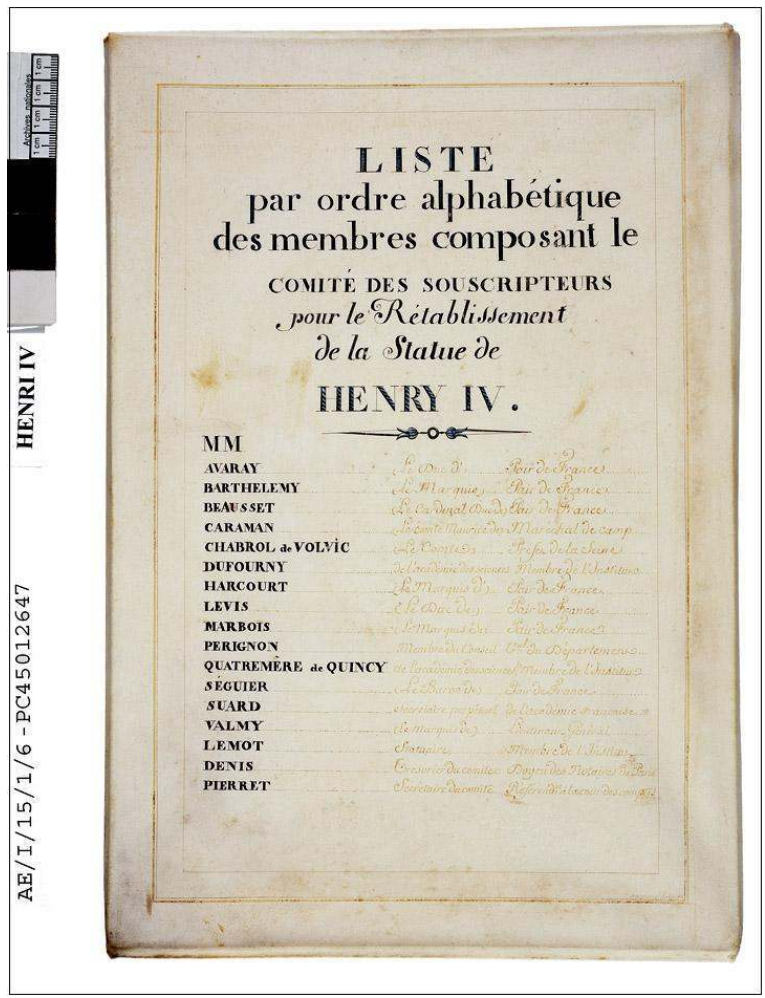

Liste des membres du comité de souscription

Phot. Département de la conservation. (c) Archives nationales, Paris

Document 3 (AE/I/15bis/1/4)

Procès-verbal de l'inauguration de la statue, le 25 août 1818

Parchemin

\section{H. $56,5 \mathrm{~cm} \times$ L. $42,4 \mathrm{~cm}$}

Procès-verbal

Ce jour d'hui mardi vingt-cinq août, mil huit cent dix-huit, en présence de sa Majesté Louis dix-huitième du nom Roi de France et de Navarre, de leurs Altesses royales et les Princes et Princesses de la famille royale, de leurs altesses sérénissimes les Princes et 
Princesses du sang, des Ambassadeurs, Ministres, grands dignitaires et autres personnes en très grand nombre invitées à la présente cérémonie

Nous, membres composant le comité des souscripteurs, après avoir pris les ordres de sa Majesté, avons procédé à l'inauguration sur le terre-plein du Pont-Neuf de la statue équestre de Henry, quatrième du nom, Roi de France et de Navarre, commencée en mil huit cent quatorze, et jet[t]ée en bronze en mil huit cent dix-sept, par le Sr Lemot, sculpteur, chevalier de l'Ordre de St Michel et de la Légion d'honneur, membre de l'Académie des Beaux-Arts et de l'Institut de France, chargé par nous au nom des dits souscripteurs de tout le travail relatif au monument de ce grand Roi.

Et à trois heures après midi, le Roi ayant donné le signal de découvrir la statue, M.M. Lerat de Magnitot, juge de paix du deuxième arrondissement, Wante, directeur des pensions au Trésor royal, Borel, secrétaire de la $1^{\text {re }}$ Présidence de la Cour des Comptes, et officier de la $1^{\text {re }}$ légion de la garde nationale, Duparc, conseiller référendaire de la dite cour et capitaine de la jème légion, Courte Epée, inspecteur des travaux du terre plain, Loiseleur, sous-inspecteur des dits travaux, Gaulier et Elie de Beaumont, élèves de l'école polytechnique, souscripteurs par nous désignés, ont abaissé les voiles qui avaient jusqu'à ce moment enveloppé la statue, et au même instant tous les assistan<t>s se sont levés et le monument a été découvert aux acclamations d'une foule immense et aux cris répétés de Vive le Roi.

Et attendu qu'un récit détaillé et circonstancié contenant tout ce qui est relatif au monument, relevé par le zèle et la piété des Français, en témoignage de leur immortelle affection et respect pour le grand Henry, est en ce moment rédigé pour être incessamment rendu public, nous avons jugé superflu de redire ici ce qui est compris au dit récit ${ }^{7}$.

Et le dit jour, à cinq heures du soir est comparu par devant nous le dit Sr Lemot, cy dessus qualifié et dénommé, lequel nous a requis acte du contenu qui précède, que nous lui avons délivré à telle fin que de raison.

Et avons signé les jour, mois et an que dessus.

<suivent les signatures des membres du comité de souscription> » 
Figure 4

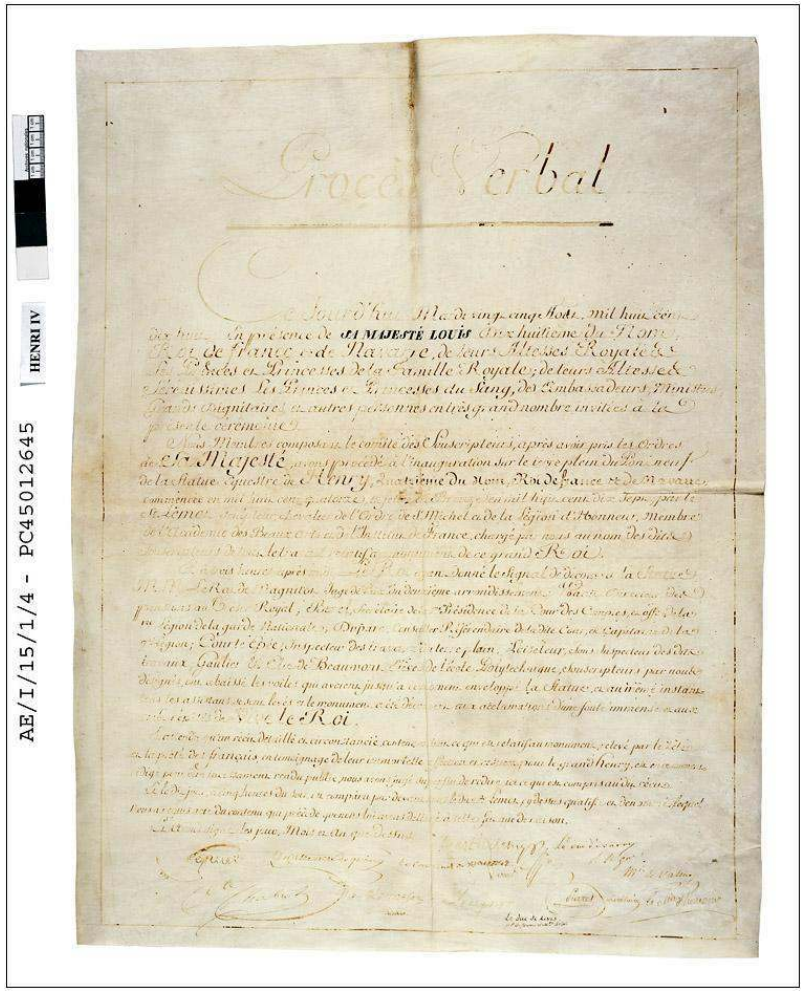

Procès-verbal de l'inauguration de la statue, le 25 août 1818

Phot. Département de la conservation. (c) Archives nationales, Paris

Document 4 (AE/I/15bis/1/5)

Notice des objets contenus dans la statue (sans date)

Parchemin

H. $42,5 \mathrm{~cm} \times$ L. $22,5 \mathrm{~cm}$

21 « Notice des objets renfermés dans le corps de la statue équestre de Henry IV

$1^{\text {ère }}$ Boëte

Une ampliation sur parchemin du procès-verbal dressé le $23^{\mathrm{e}}$ jour 1614 , lors de l'inauguration de l'ancienne statue. Une liste des membres du comité sur peau de vélin. Le procès-verbal dressé le 25 août 1818, jour de l'Inauguration de la nouvelle statue.

$2^{\mathrm{e}}$ Boëte

Les économies royales de Sully. 2 vol. in fo. Édition connue sous le titre Der w verts (?) reliés en veau fauve avec dentelles, compartimens, tranche dorée et armes de France par Simier Relieur du Roi.

$3^{\mathrm{e}}$ Boëte

Un exemplaire de la Henriade, en 2 volumes grand in $8^{\circ}$ et sur peau de vélin. Édition de Beaumarchais. Reliés par Simier en maroquin bleu, avec dentelles. Compartimens et armes de France.

$4^{e}$ Boëte

Un exemplaire de la vie de Henry IV, par Péréfixe 1 vol. grand in $8^{\circ}$ papier vélin Édition de Renouard, relié par Simier en maroquin vert, avec dentelle et tranche dorée. Plus 26 médailles désignées en la notice cy-dessous (A).

A Notice des 26 médailles insérées dans la $4^{e}$ Boëte 


\begin{tabular}{|c|c|c|c|}
\hline & & En argent & En bronze \\
\hline \multirow{10}{*}{ Médailles de 18 ligniées } & Retour de Louis XVIII en France & 1 & I \\
\hline & Entrée du Roi a Paris & I & I \\
\hline & La charte constitutionnelle & 1 & 1 \\
\hline & La Légion d'Honneur & $\mathbf{I}$ & I \\
\hline & Le 3 mai 1814 & I & I \\
\hline & Pompe funebre de Louis XVI <et> & & \\
\hline & Marie Antoinette & I & I \\
\hline & Mariage du Due de Berry & 1 & 1 \\
\hline & Portrait de Malherbe & 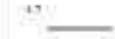 & 3 \\
\hline & & 7 & 8 \\
\hline
\end{tabular}

\begin{tabular}{|l|l|c|c|}
\hline & En argent & En bronze \\
\hline \multirow{4}{*}{ Médailles de 22 lignées } & Paix du 12 mai 1814 & I & I \\
\cline { 2 - 4 } & 20 mars 1815 & I & I \\
& Retour du 8 juillet 1815 & I & I \\
& Le 21 janvier 1817 & 1 & I \\
& La statue équestre de Henry IV & I & I \\
& & 5 & 5 \\
\hline
\end{tabular}

Plus une médaille en platine de la Statue équestre, exécutée par M. M. Cuocq A. Couturier de Lyon

En argent 12

Médailles En bronze 1326

En platine 1 » 


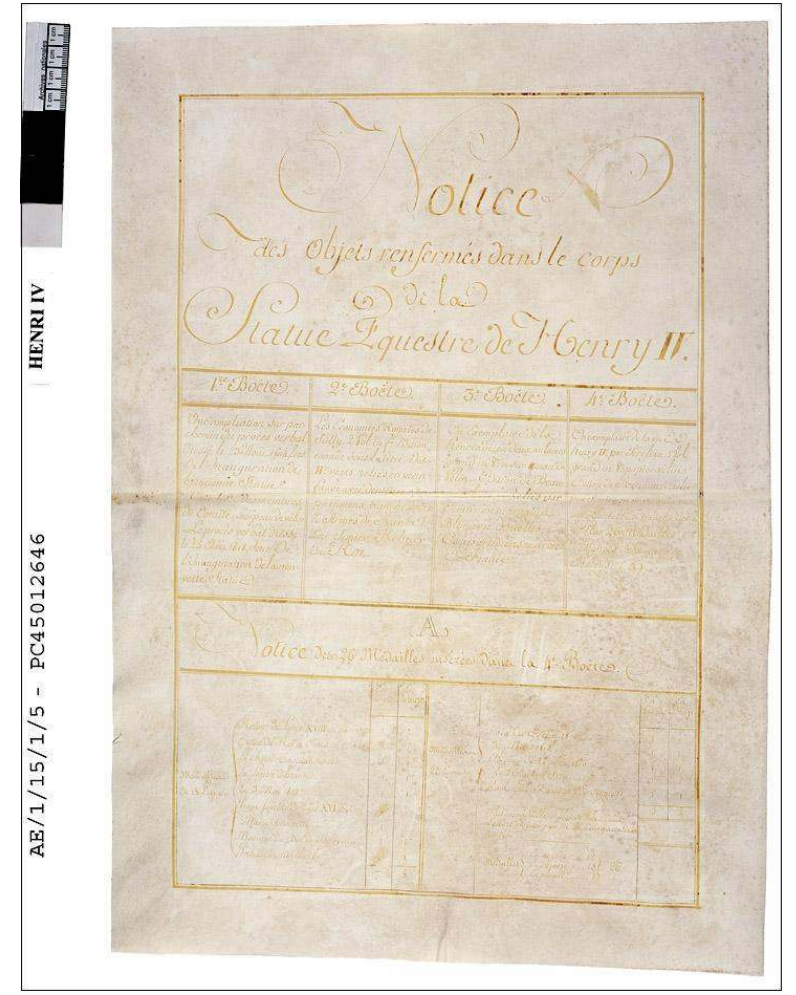

Notice des objets insérés dans la statue

Phot. Département de la conservation. (c) Archives nationales, Paris

Boîte 1, Document 5

$\mathrm{AE} / \mathrm{I} / 15 \mathrm{bis} / 1 / 2$

Récit du transport et de la mise en place de la statue d'Henri IV, depuis la Fonderie du Roule jusqu'au Pont-Neuf en 1818

Parchemin (2 ff.)

H. $32 \mathrm{~cm} \times$ L. $24,5 \mathrm{~cm}$

«/f. 1r/ L'an mil huit-cent dix-huit, le quatorze août neuf heures du matin, en présence de Monsieur le Marquis de Marbois Pair de France, premier président de la Cour des Comptes de Paris, président du comité des souscripteurs pour la réedification de la statue d'Henri quatre, sur le terre-plein du Pont-Neuf, de Monsieur le Comte Chabrol de Volvic, Conseiller d'Etat-Préfet du département de la Seine, de son Excellence le Comte Anglès, Ministre d'Etat Préfet de police, de Monsieur Quatremère de Quinci, Secrétaire perpétuel de l'Académie des beaux-arts de l'Institut et de Monsieur Du Fourny, membre de l'Institut et professeur d'architecture à l'Ecole royale des beaux-arts, il été procédé au transport de la statue équestre d'Henri quatre. Cette statue en bronze devant être conduite de l'atelier $\mathrm{du}$ Roule, dans lequel elle a été fondue, au terre-plein du Pont-Neuf, où elle doit être définitivement placée, a parcouru successivement, et de suite, le faubourg du Roule, la place Beauveau et une partie de l'avenue de Marigny. Cette avenue n'ayant qu'une chaussée étroite et bombée a présenté des difficultés pour le tirage et des obstacles pour la direction du traîneau, qui en ont retardé la marche, de sorte qu'on n'est arrivé qu'à six heures du soir dans la grande avenue des Champs Elysées. Là le peuple, par un mouvement spontané, s'est saisi des cordages où étaient attelés les bœufs, et en un instant la statue, /f. 1v/ arrivée à la place Louis quinze a traversé cette place sans aucun 
obstacle jusqu'au pont de Louis seize. Alors le nombre de personnes qui voulaient coopérer à la conduite de cette statue, s'étant considérablement accru, les bœufs ont été dételés avec précipitation, le traîneau a été remis en route le long du quai des Tuileries et a fait une station au pavillon de Flore. Sa Majesté, accompagnée de son auguste famille a paru en ce moment aux fenêtres de ce pavillon, des cris mille fois répétés de «Vive le Roi ", se sont fait entendre de toute part, après quoi la marche a continué, et le traineau est parvenu au pont des Arts, après avoir mis une heure au plus à parcourir l'espace de la grande avenue des Champs Elysées jusqu'à ce pont, mais la nuit qui s'avançait a obligé de remettre le reste du chemin à faire jusqu'au lendemain, ce qui n'a pu être effectué que le lundi à cause de l'occurrence de la fête de L'assomption et du dimanche suivant.

Le dit jour lundi dix-sept août, tous les préparatifs pour cette dernière partie de transport étant terminés dès trois heures du matin, et les tonneaux d'arrosement dont on s'étoit servi dans la première partie du trajet ayant de l'avis et d'après l'ordre de son excellence le Préfet départemental été remplacés par des pompes à incendie, le départ n'a pu avoir lieu qu'à cinq heures à cause de la difficulté de rassembler le nombre complet des chevaux qui devoient l'exécuter en remplacement des bœufs, qui sur /f. 2 r/ une route pavée n'auroient pu faire le même usage de leur force que sur terre. La marche s'étant donc ouverte à cinq heures, la statue a été rendue à sa destination, sur le terre-plein du Pont-Neuf, à six heures et un quart du matin.

Aussitôt il a été fait une visite exacte de cette statue par Monsieur Lemot, sculpteur, chevalier de l'Ordre de St Michel et de la Légion d'honneur, membre de l'Académie des beaux-arts et de L'Institut de France, à qui on doit l'exécution de ce monument, et par Monsieur Molinos, chevalier de la Légion d'honneur, architecte inspecteur général des travaux publics du département de la Seine et de la Ville de Paris, lequel a été chargé par Monsieur le Comte de Chabrol, conseiller d'Etat, Préfet du département de la Seine, de surveiller le transport de la statue dont Monsieur Guillaume ancien charpentier avait conçu et exécuté l'armature et le traîneau sur lequel elle a été placée. Messieurs Lemot et Molinos, après avoir reconnu que la dite statue n'avait été endommagée en aucune partie et qu'elle se trouvait sur le terre-plein du Pont-Neuf, dans le même état où elle était à son départ de la fonderie du Roule, ont signé le présent procès-verbal.

À Paris le dix-sept août sept heures du matin

<signatures de Molinos et Lemot>»

Ce document n'est pas recensé parmi les objets listés dans la notice précédente (AE/ $\mathrm{I} / 15 \mathrm{bis} / 1 / 5)$. Peut-être a-t-il été ajouté après la constitution et le recensement des pièces de la boîte 1, sur la demande expresse de Lemot, co-signataire du procès-verbal. En revanche, le procès-verbal du 25 août 1818 (AE/I/5/1/4) en fait mention. 
Figure 6

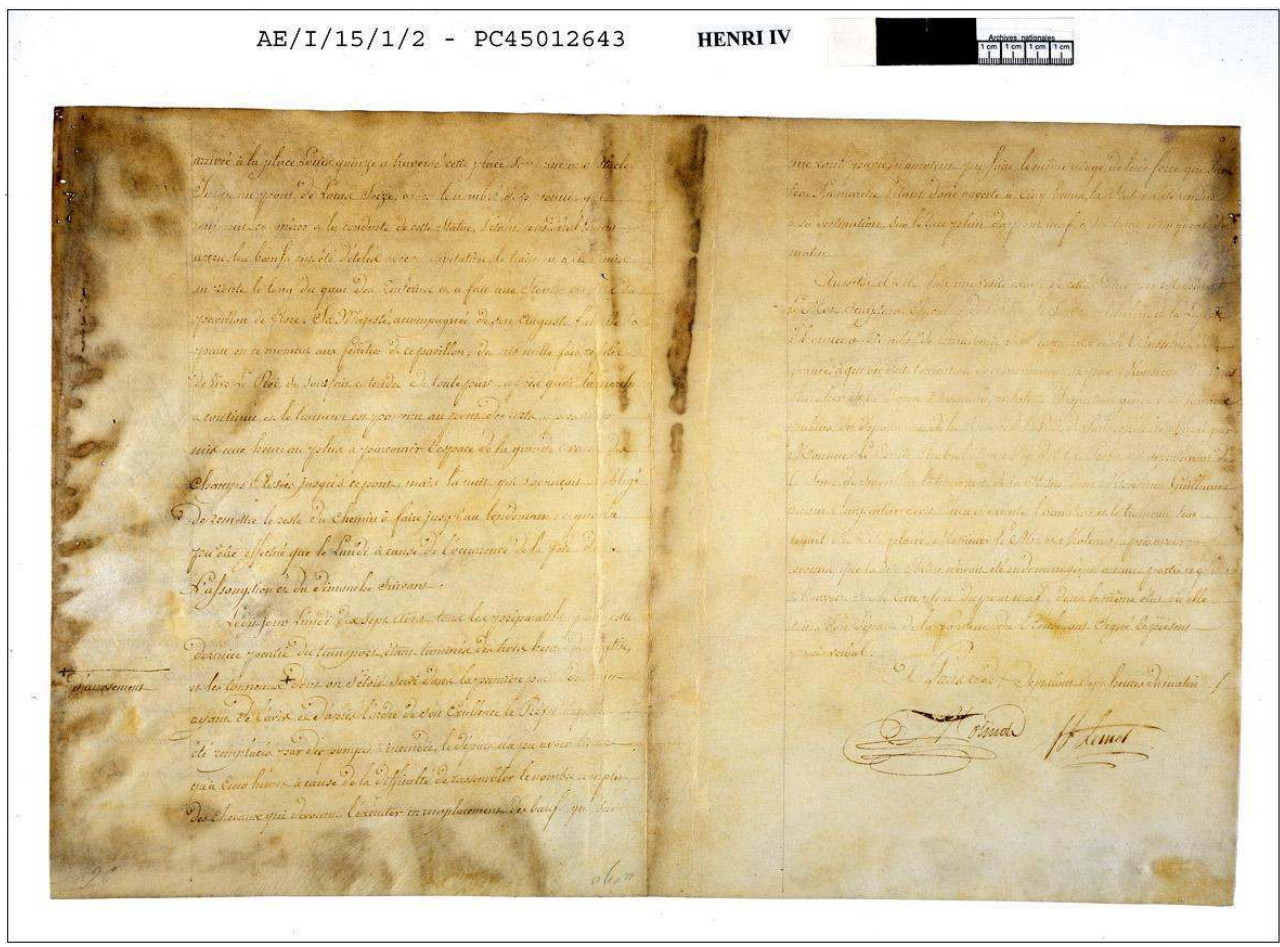

Récit du transport et de la mise en place de la statue

Phot. Département de la conservation. (c) Archives nationales, Paris

Boîte $n^{\circ} 2(\mathrm{AE} / \mathrm{I} / 15 \mathrm{bis} / 2 / 1)^{8}$ 


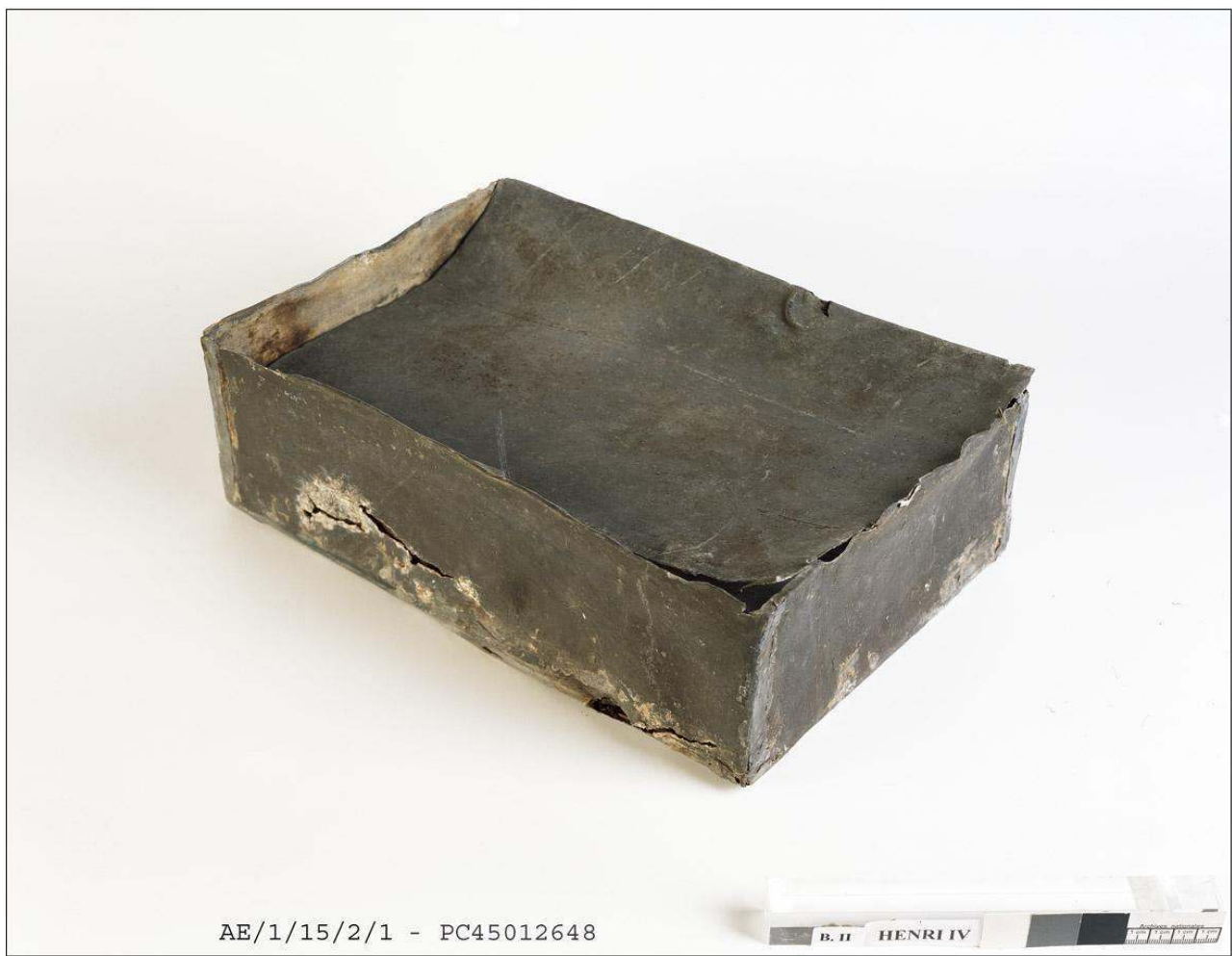

Boîte $n^{\circ} 2$

Phot. Département de la conservation. (C) Archives nationales, Paris

Boîte $\mathrm{n}^{\circ} 2$, contenu

$\mathrm{AE} / \mathrm{I} / 15 \mathrm{bis} / 2 / 2$

Maximilien de Béthune, duc de Sully, Économies royales (édition non identifiée)

In folio

H. $32 \mathrm{~cm}$ x L. $21,5 \mathrm{~cm}$ x ép. $8,5 \mathrm{~cm}$

2 volumes reliés par Simier

veau rouge et dorures, armes de France

La reliure de Simier, maître relieur du roi, « en veau fauve avec dentelles, compartimens, tranche dorée et armes de France » a été très endommagée par l'eau. Un seul des deux corps d'ouvrage, en très mauvais état, a été conservé. 
Figure 8

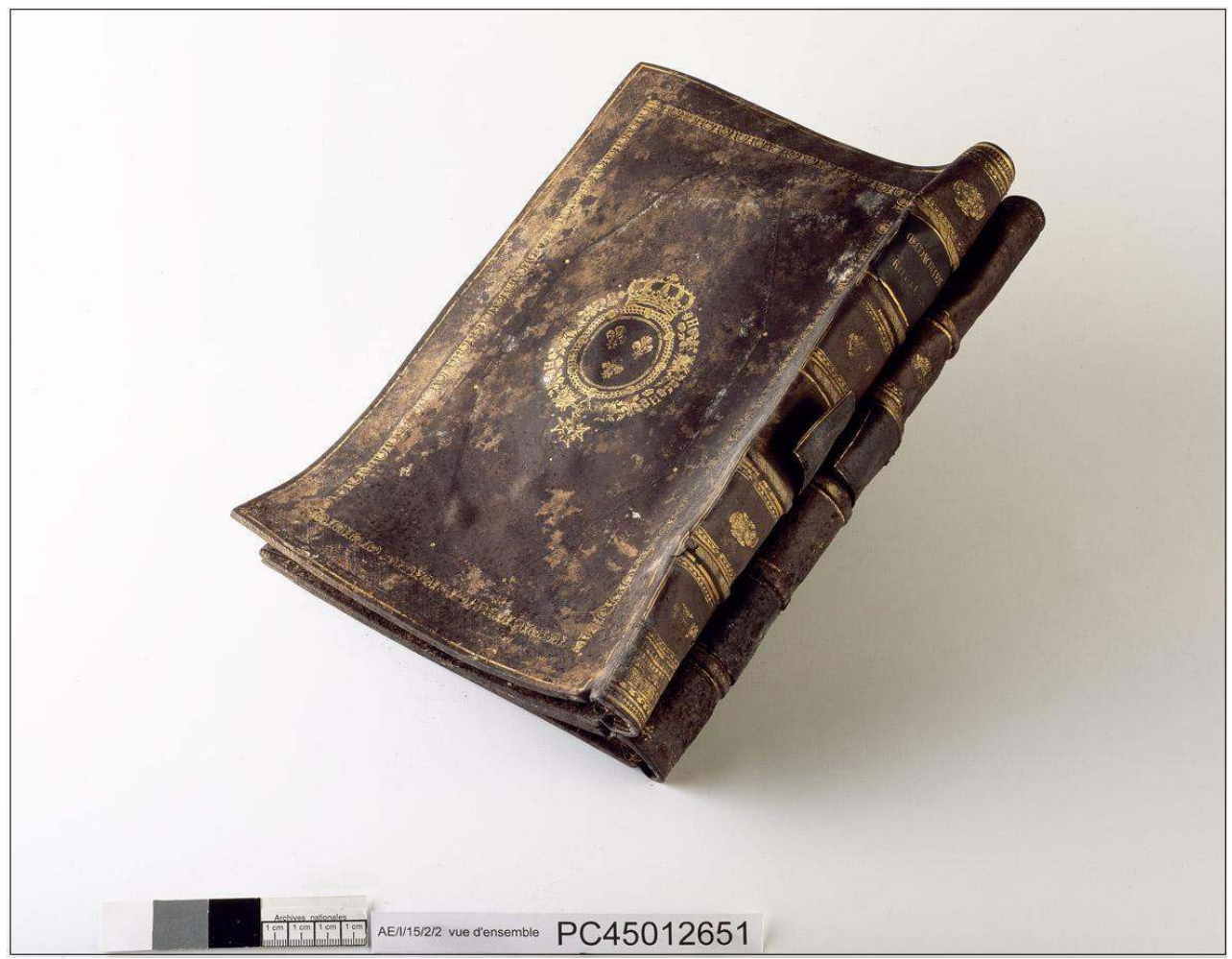

Les Économies royales

Phot. Département de la conservation. ( ) Archives nationales, Paris

Boîte $n^{\circ} 3(\mathrm{AE} / \mathrm{I} / 15 \mathrm{bis} / 3 / 1)^{9}$ 
Figure 9

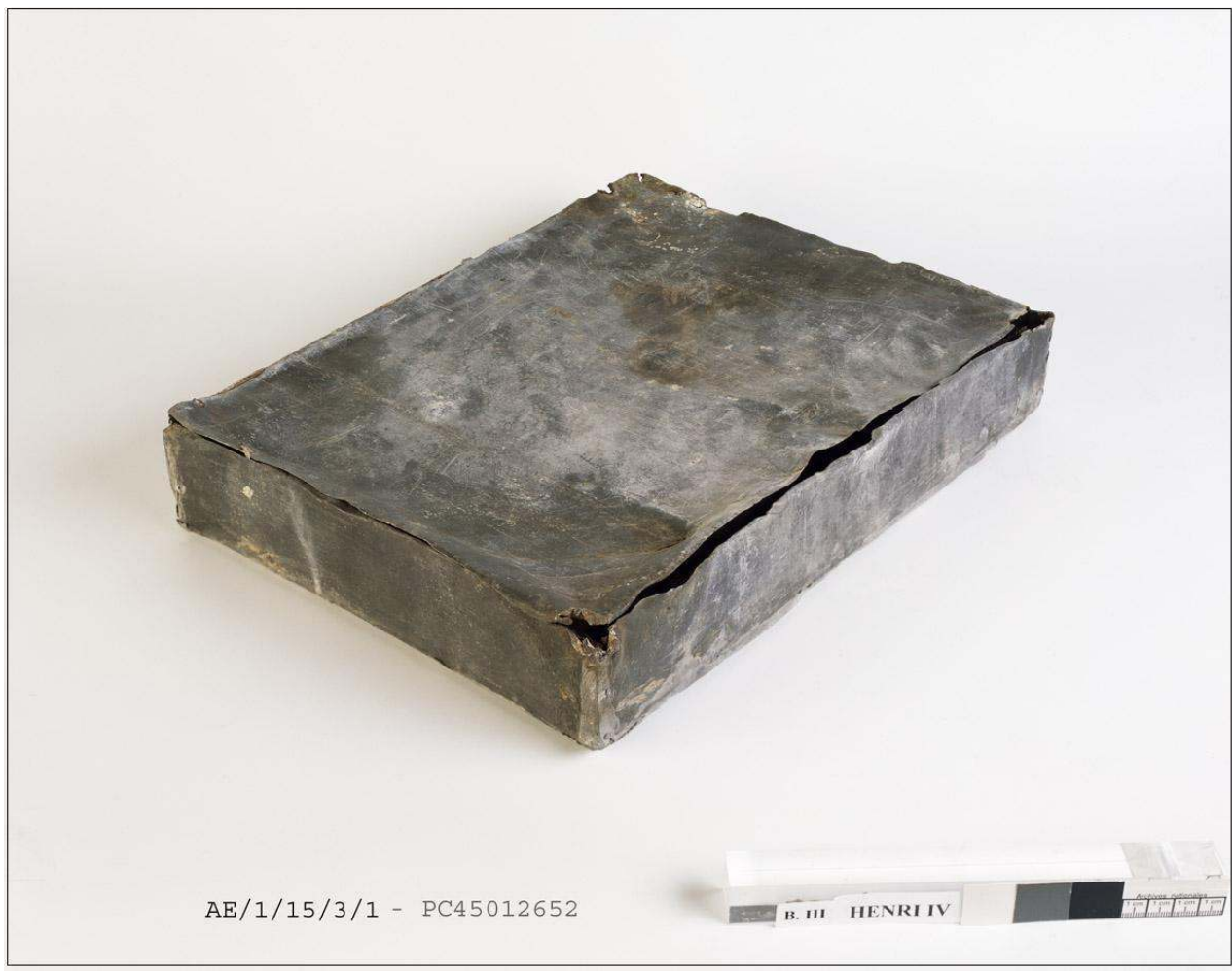

Boîte $n^{\circ} 3$

Phot. Département de la conservation. (C) Archives nationales, Paris

Boîte $n^{\circ} 3$, contenu

$\mathrm{AE} / \mathrm{I} / 15 \mathrm{bis} / 3 / 2$, volumes 1 et 2

Voltaire, La Henriade

édition Beaumarchais, année inconnue <Kehl, 1779>

$\operatorname{In} 8^{\circ}$

Volume $1:$ H. 25,5 cm x L. $18 \mathrm{~cm}$ x ép. $5,5 \mathrm{~cm}$

Volume $2:$ H. $24 \mathrm{~cm} \times$ L. $15 \mathrm{~cm}$ x ép. $3,5 \mathrm{~cm}$

reliure de maroquin bleu (disparue)

La reliure par Simier « en maroquin bleu, avec dentelles, compartimens et armes de France » a entièrement disparu, soit par décomposition, soit par agglutination avec un des pans de la boîte en bois. 


\section{Figure 10}

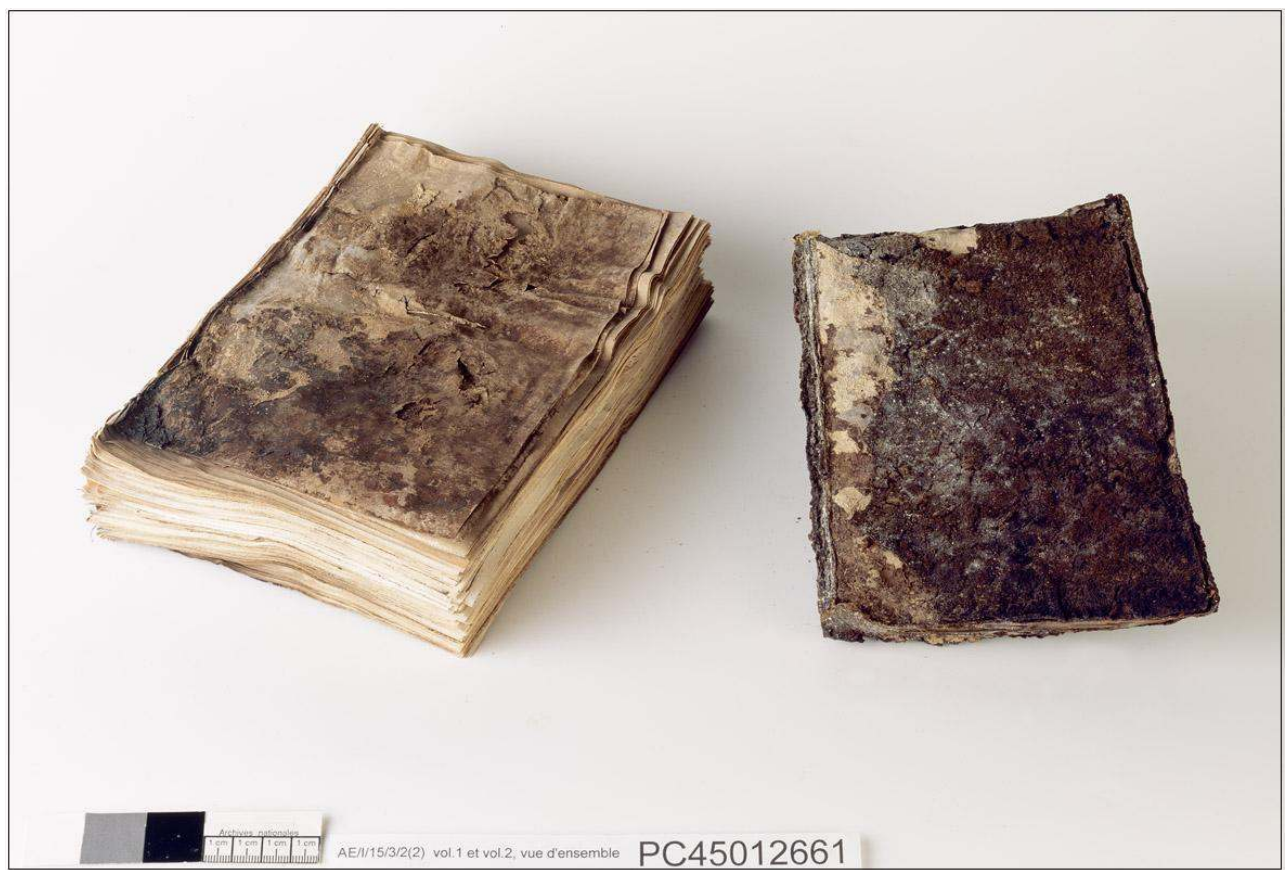

La Henriade

Phot. Département de la conservation. (c) Archives nationales, Paris

Boîte $n^{\circ} 4(\mathrm{AE} / \mathrm{I} / 15 \mathrm{bis} / 4 / 1)^{10}$

Figure 11

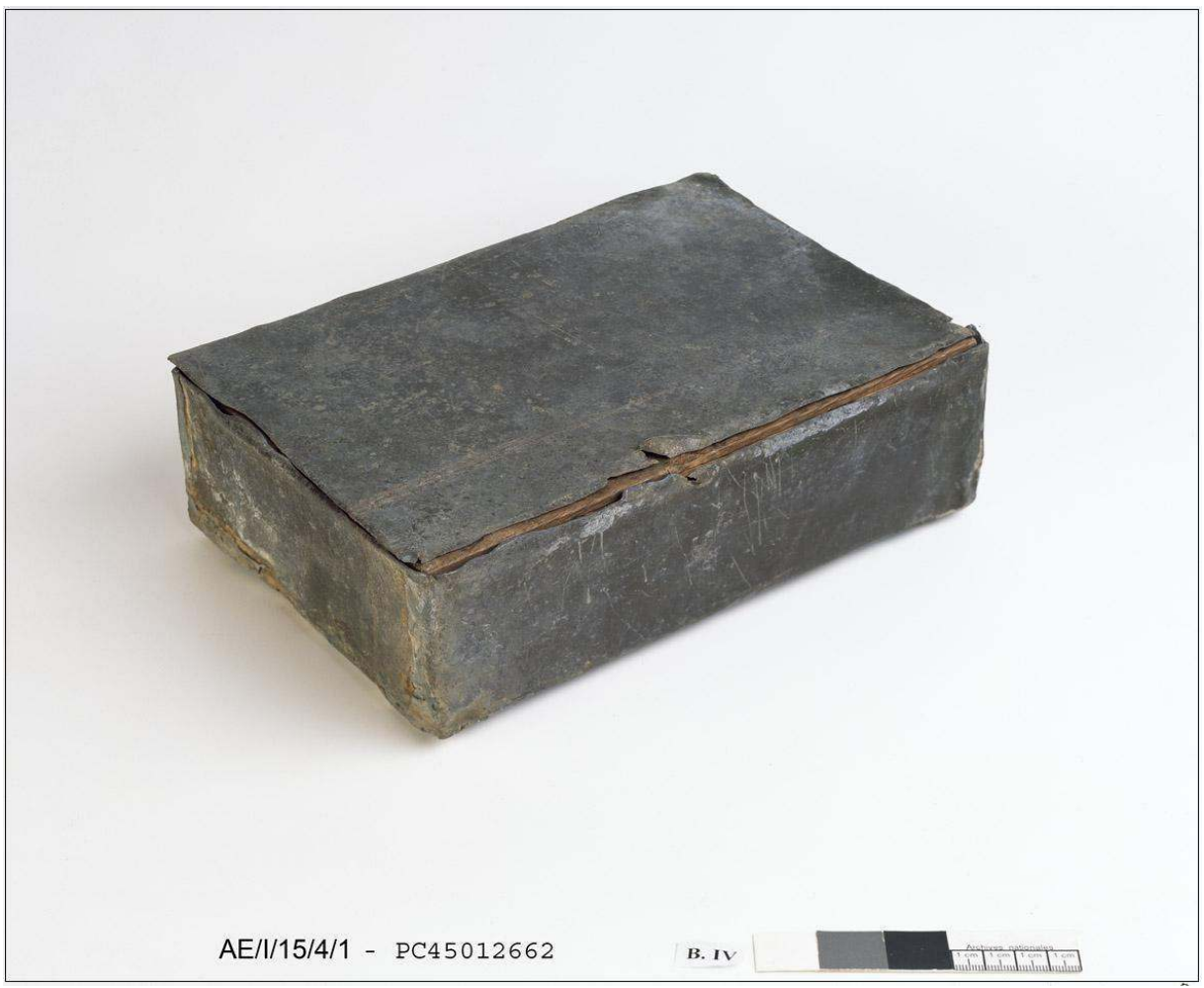

Boîte $n^{\circ} 4$

Phot. Département de la conservation. (c) Archives nationales, Paris 
$\mathrm{AE} / \mathrm{I} / 15 \mathrm{bis} / 4 / 2$

Hardouin de Péréfixe, Histoire du roi Henri le Grand

édition A.-A. Renouard, Paris, 1816

In $8^{\circ}$, maroquin vert orné à chaud sur la tranche et dentelle

H. 23,2 cm x L. 15,2 cm x ép. 4,3 cm

Figure 12

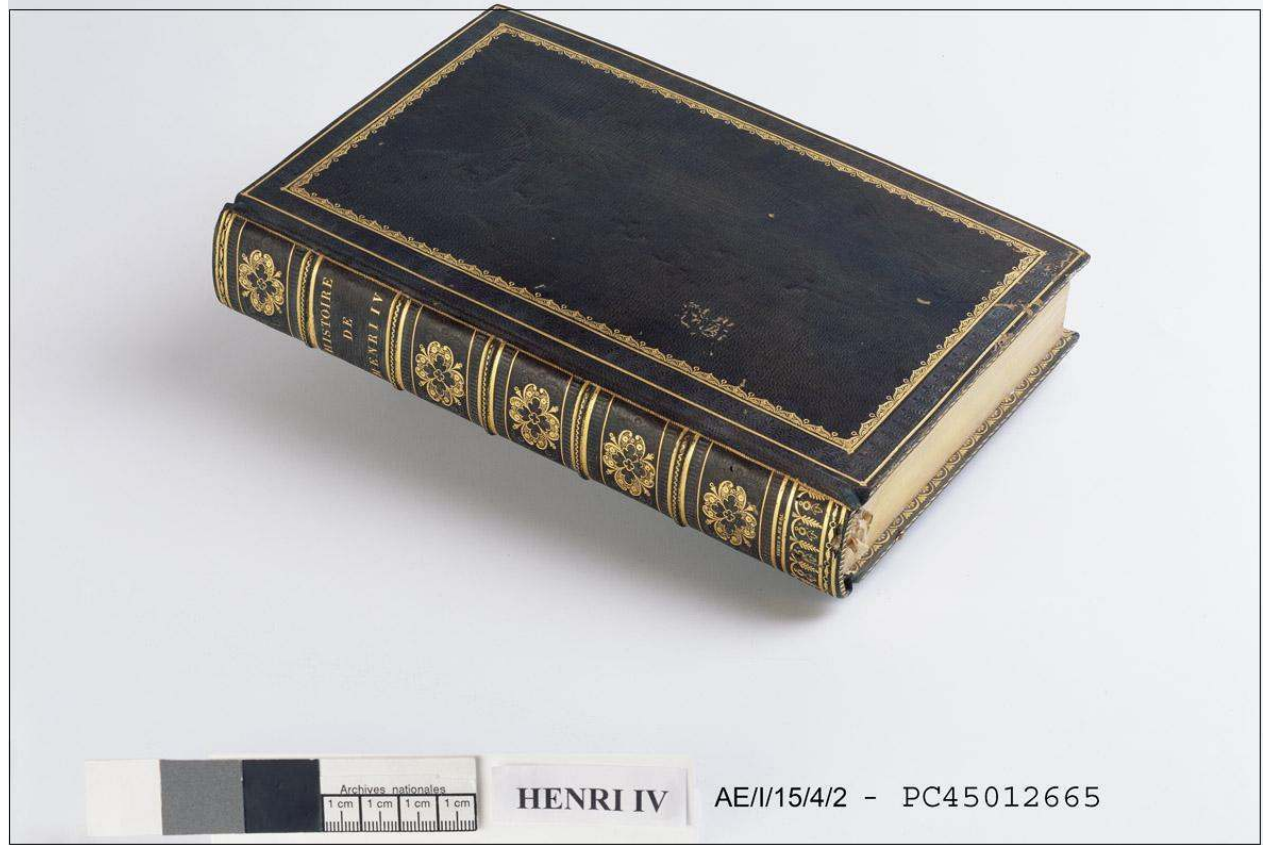

Hardouin de Péréfixe, Vie de Henri le Grand

Phot. Département de la conservation. (C) Archives nationales, Paris

$\mathrm{AE} / \mathrm{I} / 15 \mathrm{bis} / 4 / 3$

26 médailles disposées dans leur conditionnement d'origine

argent : 12 pièces

bronze : 13 pièces

platine : 1 pièce 
Figure 13

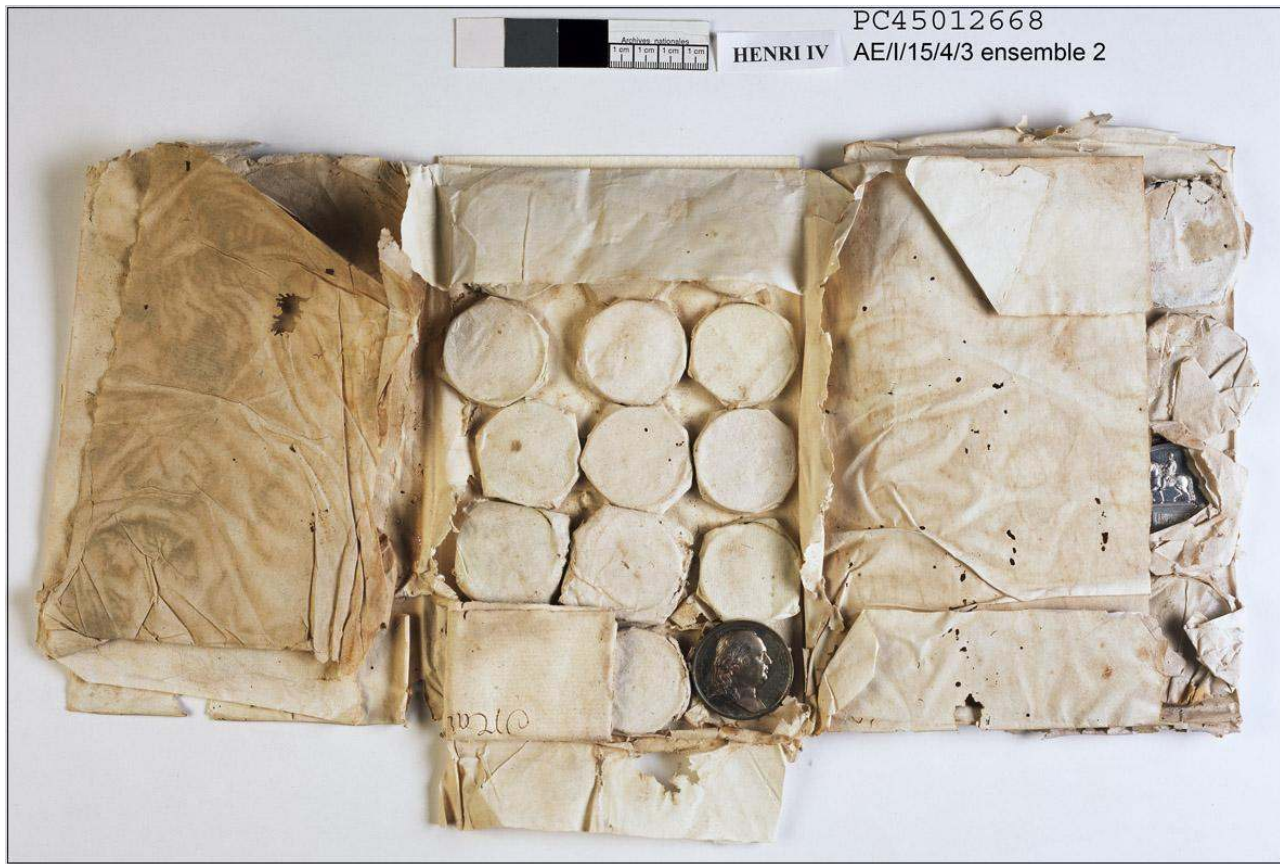

Le médailler

Phot. Département de la conservation. (c) Archives nationales, Paris

\section{Objets retrouvés dans le cavalier}

$\mathrm{AE} / \mathrm{I} / 15 \mathrm{bis} / 5 / 1$

Boîte cylindrique. Couvercle portant gravée l'inscription « Mesnel ».

Étain ? Papier collé sur la paroi intérieure, colle animale

H. $7,3 \mathrm{~cm} \times$ L. $6,4 \mathrm{~cm}$ 


\section{Figure 14}

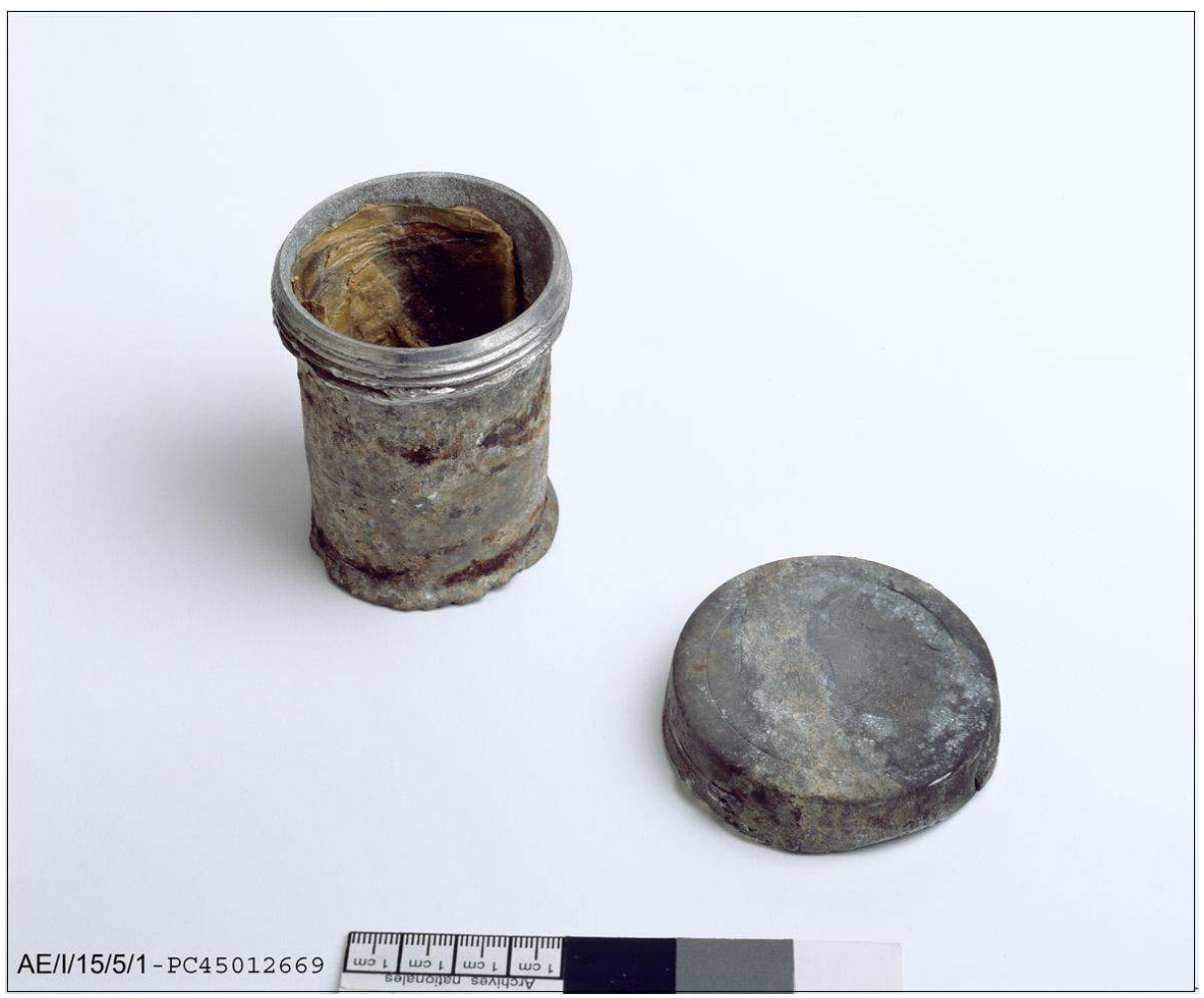

Étui d'étain portant gravé le nom de Mesnel

Phot. Département de la conservation. (c) Archives nationales, Paris 
Figure 15

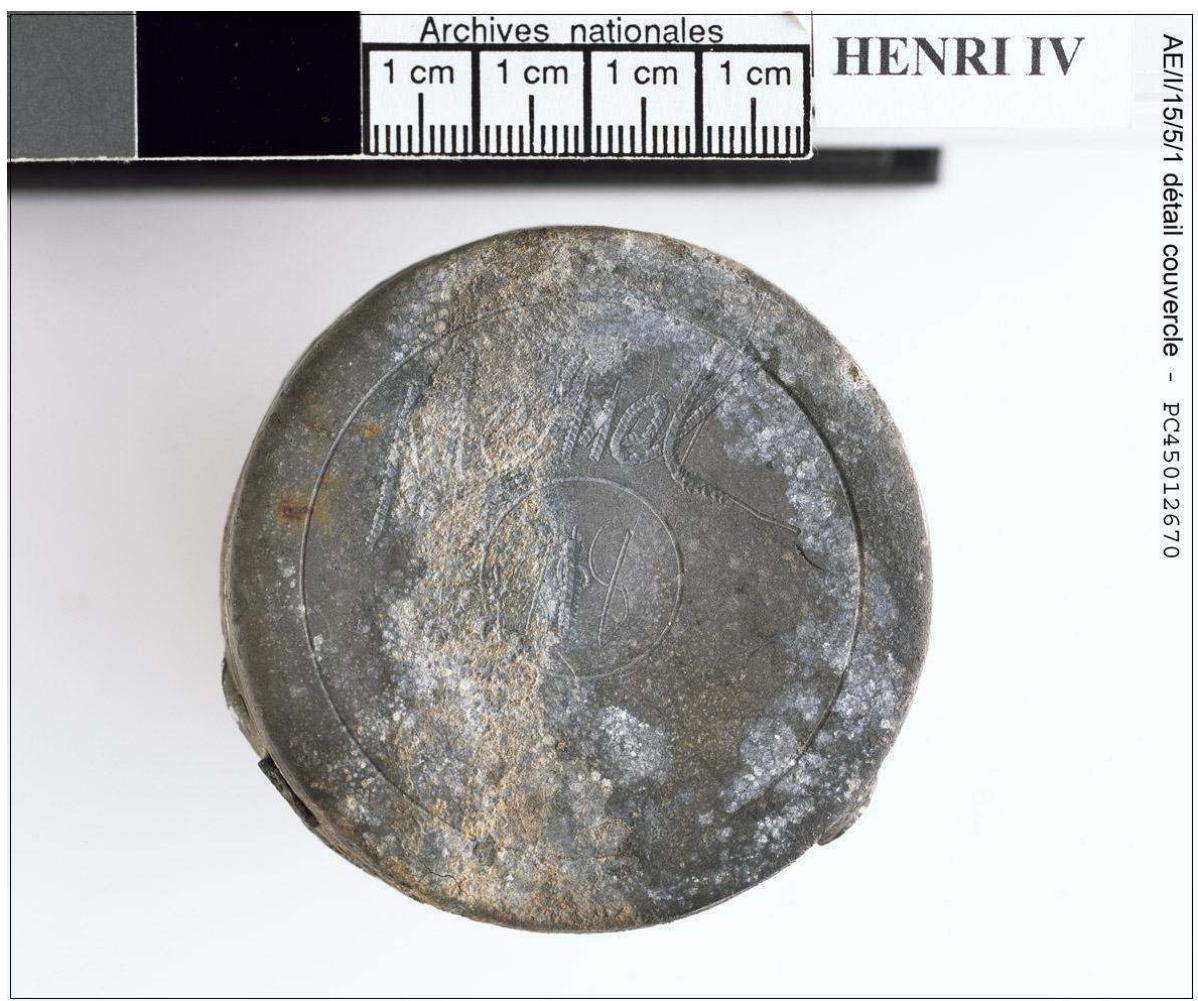

Détail de l'étui d'étain : vue du couvercle

Phot. Département de la conservation. ( ) Archives nationales, Paris

$\mathrm{AE} / \mathrm{I} / 15 \mathrm{bis} / 5 / 2$

Boîte cylindrique à couvercle

Étain?

H. $4,3 \mathrm{~cm} \times$ L. $3,5 \mathrm{~cm}$

$\mathrm{AE} / \mathrm{I} / 15 \mathrm{bis} / 5 / 3$

Rouleau de papier 
Figure 16

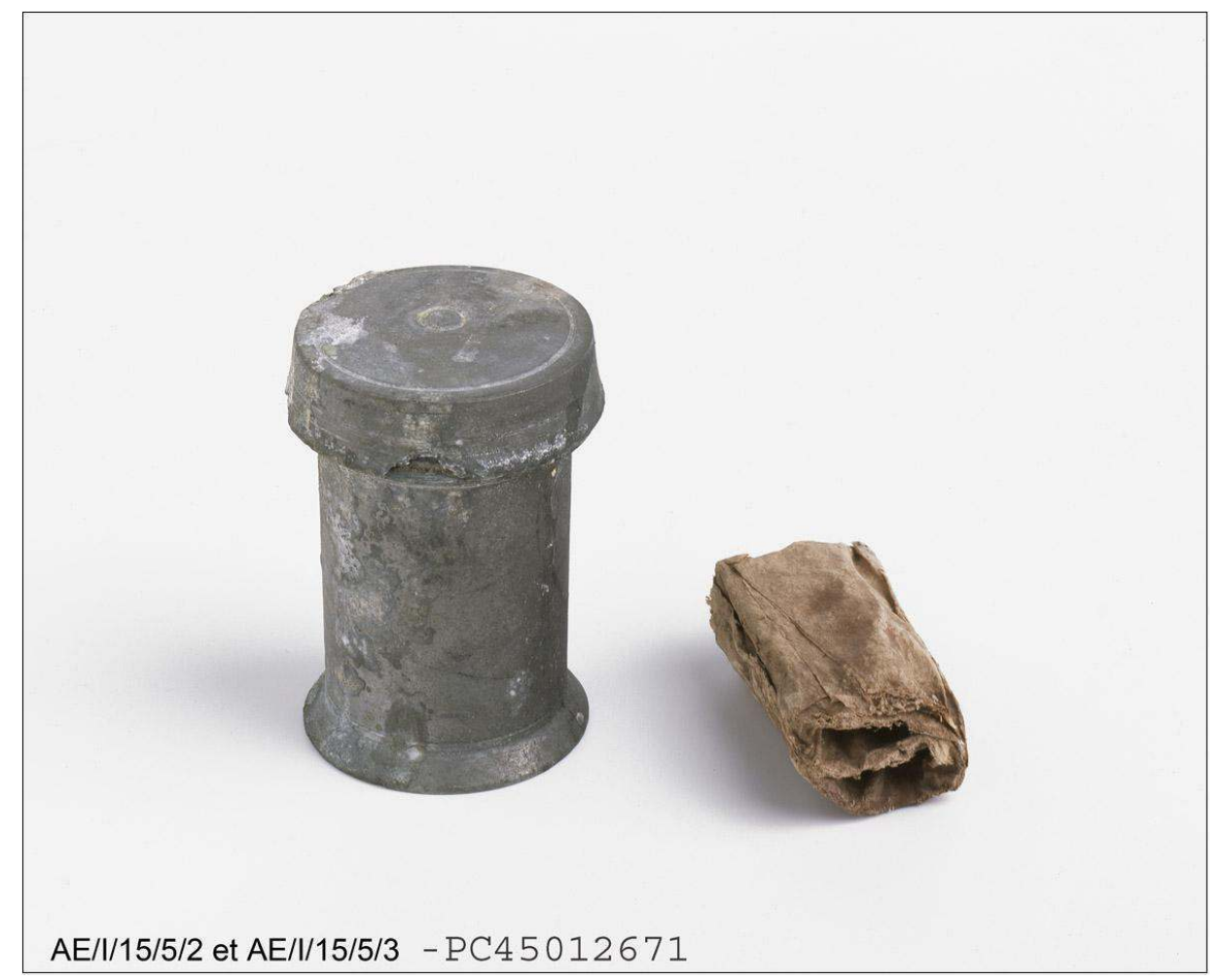

Boîte d'étain et son contenu

Phot. Département de la conservation. ( ) Archives nationales, Paris

$\mathrm{AE} / \mathrm{I} / 15 \mathrm{bis} / 5 / 4$

Étui cylindrique

Bois

H. $12 \mathrm{~cm} \mathrm{X} \mathrm{L.} 3 \mathrm{~cm}$ 
Figure 17

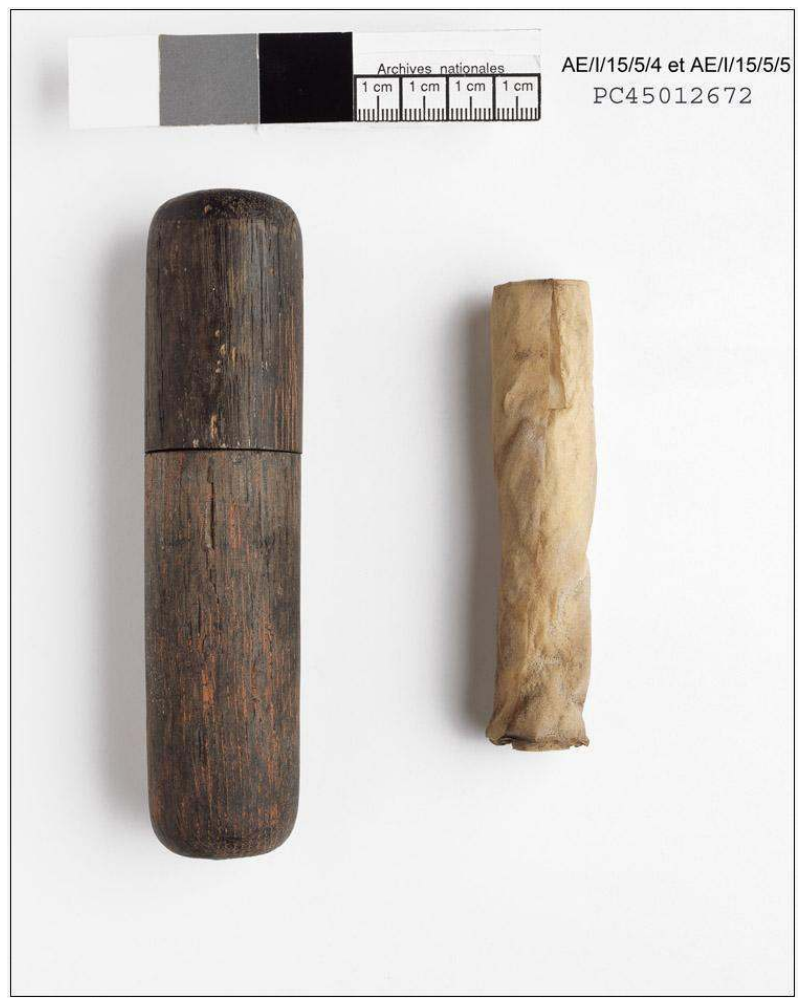

Étui de bois et son contenu

Phot. Département de la conservation. (c) Archives nationales, Paris

$\mathrm{AE} / 15 \mathrm{bis} / 5 / 5$

Rouleau de parchemin disposé à l'intérieur de l'étui cylindrique en bois et portant la liste des ouvriers ayant travaillé à la réalisation de la statue sous la direction de Baltazar Mesnel.

Parchemin

H. $44,7 \mathrm{~cm} \times$ L. $13,5 \mathrm{~cm}$ 
Figure 18

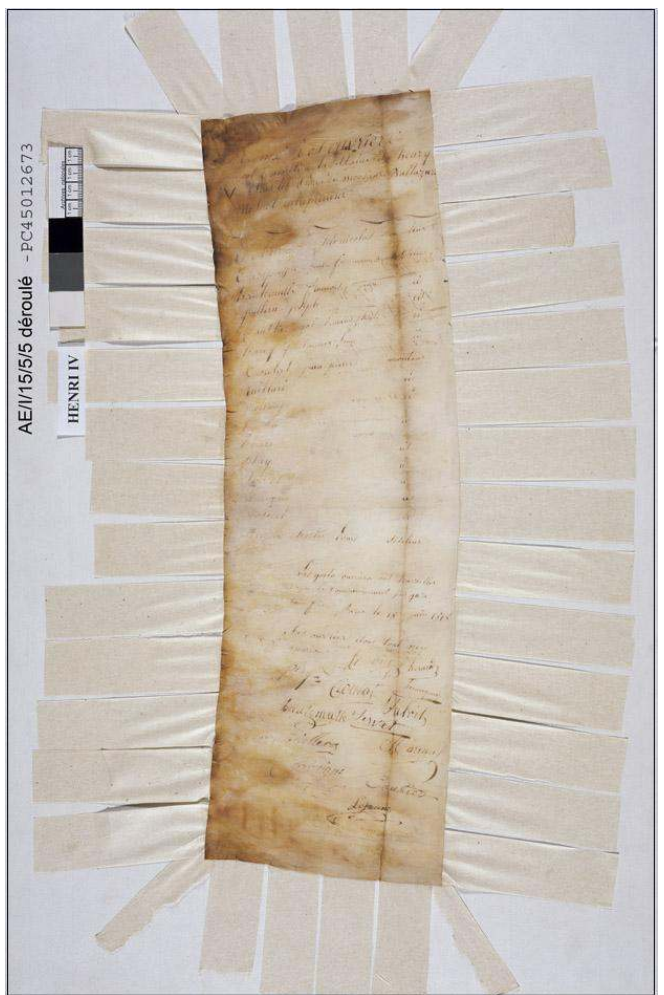

Rouleau de parchemin portant la liste et les signatures des fondeurs et ciseleurs du Roule Phot. Département de la conservation. (c) Archives nationales, Paris

La multitude et la variété de ces objets commémoratifs sont sans précédent. Quel contexte, quelles raisons conjoncturelles permettent de l'expliquer?

\section{L'émergence de nouvelles pratiques, fin XVIII e-début $\mathrm{XIX}$ : le « trésor mémoriel »}

Parallèlement à la pratique, déjà ancienne, qui consiste à enfermer un document commémoratif dans un monument public, se multiplient à partir de la fin du XVIII ${ }^{\mathrm{e}}$ siècle les memorabilia, ensembles mémoriels à la gloire d'un personnage historique, et qui peuvent prendre la forme de reliquaires ou de mausolées symboliques. La constitution du musée des Monuments français par Alexandre Lenoir, qui collecte sous prétexte de les préserver des éléments architecturaux et mobiliers des édifices religieux et des sépultures de personnages célèbres, joue sans doute un rôle important dans la multiplication de ces memorabilia ${ }^{11}$.

Pour alimenter ces trésors mémoriels, des objets de nature diverse peuvent être convoqués, qui, par-delà toute visée historique et pédagogique, sont censés frapper l'imagination des contemporains en faisant appel à leur sensibilité. Parmi ces objets, le reliquaire « laïque » occupe une place de choix. Largement pratiqué par Lenoir lui-même, il est alimenté par les nombreux transferts de sépultures opérés par le directeur du musée des Monuments français à l'occasion de ses "prélèvements" architecturaux. 
Henri IV lui-même est l'objet, lors de son exhumation à Saint-Denis, en 1793, du trafic de reliques auquel se livrent Lenoir et d'autres.

Ainsi des restes du roi viennent prendre place, entre ceux du Cid et de Chimène, d'Héloïse et d'Abélard, de Molière, La Fontaine et Voltaire, dans le reliquaire constitué par Vivant Denon, au sein d'une pièce d'orfèvrerie ancienne provenant d'Espagne. Le reliquaire comme trésor mémoriel est alors prétexte à tous les raccourcis, constituant une forme de panthéon laïque en miniature qui ne dépare pas l'entreprise de Lenoir aux PetitsAugustins.

\section{Hagiographie}

31 C'est dans ce contexte qu'a lieu la «restauration» de 1818. Car de 1814, date de l'inauguration de la statue provisoire (et par conséquent moins importante au plan symbolique), à 1818, la typologie des objets enfermés dans la statue s'est beaucoup enrichie.

Surtout, la statue définitive renferme une catégorie de pièces dont l'usage en de telles circonstances n'est pas attesté jusque lors: des imprimés somptueusement reliés d'œuvres littéraires, enchâssés, tels des reliques, dans leurs boîtes de plomb.

L'ensemble des pièces officiellement enfermées dans la statue vise à prendre acte d'un fait historique que l'on veut ériger en événement. Mais l'insertion d'ouvrages littéraires ajoute à la simple commémoration une visée historiographique et hagiographique. Il s'agit manifestement de constituer ou de s'approprier un mythe dont on maitriserait les signes constitutifs, depuis l'effigie du "héros » jusqu'à l'hagiographie laïque s'y rapportant, même si, en la matière, on est prêt à faire coexister des sources autrefois considérées comme antinomiques, mais pour ce susceptibles de manifester le pouvoir fédérateur de la figure d'Henri IV.

Comme le calice enfermé dans la maçonnerie d'une église à la fois signifie et consacre sa vocation, signe performatif ainsi assumé comme tel, de même le livre donne au premier Bourbon sa dimension légendaire, quasi-mythique, de roi universel : roi gestionnaire, dont l'œuvre imprègne les Économies royales de Sully, modèle pour la dynastie à venir, élevé au pinacle par Hardouin de Péréfixe, héros épique célébré par Voltaire. En 1818, et après l'épisode révolutionnaire et l'Empire, la justification d'une statuaire royale traditionnelle est devenue plus problématique, moins naturelle. Le " trésor » inséré dans la statue sert alors, en quelque sorte, à la consacrer, concourt à sa légitimation. Si c'est un roi que l'on célèbre, c'est aussi et surtout un grand homme que la postérité peut acclamer pour ses mérites politiques. C'est d'un même élan, à la fois hagiographique et littéraire, que participera l'insertion, a posteriori, dans la statue de Napoléon par Bosio, érigée en 1804 à Boulogne, et couronnée en 1840 au moment du retour des cendres, d'un poème de Victor Hugo à la gloire de l'Empereur ${ }^{12}$.

La portée sémiotique de cette insertion documentaire n'a pas échappé aux artisans qui travaillèrent sous la direction de Baltazar Mesnel, ciseleur, à la fonte de la statue équestre. C'est sans doute pour faire pendant à l'insertion, par les souscripteurs, des documents précédemment évoqués, qu'ils ont ajouté dans la tête du cavalier trois boîtes secrètes. 


\section{Signatures} en dehors du chantier d'Henri IV, avant 1910. C'est en Italie, à Rome, que les restaurateurs, dirigés par Carlo Usaï également chargé de la restauration de la statue du Pont-Neuf, ont extrait du monument équestre élevé en l'honneur de Victor-Emmanuel II deux pièces d'intérêt majeur. Il s'agit, d'une part, d'un dessin aquarellé de la statue accompagné des signatures de tous les ouvriers, et d'autre part d'une photographie des mêmes ouvriers attablés ensemble. La photo, datée par une annotation manuscrite à l'encre de 1910, a vraisemblablement été prise à l'intérieur même du cheval. Quant aux signatures des ouvriers, elles sont précédées de la mention suivante :

" Prima di seguire la chiusura dell'ultima parte della statua Equestre, i sottoscritti hanno brindato al fonditore G. B. Bastianelli, et ai cooperatori tutti della grandiosa opera d'arte. »

Outre le témoignage qu'il apporte sur l'appropriation de l'œuvre par ses réalisateurs, l'ensemble découvert dans le cavalier semble avoir lui aussi une vocation mémorielle particulière.

\section{Un reliquaire bonapartiste?}

Si l'une des petites boîtes enfermées dans la tête de la statue renfermait la liste des ouvriers, le contenu des deux autres reste mystérieux. Il l'est d'autant plus que les «confessions» de Mesnel dans son journal posthume peuvent toujours laisser croire qu'un pamphlet bonapartiste se trouvait dans la statue. Un rouleau de papier n'a pu à ce jour être déroulé : peut-être comporte-t-il les libelles supposés. En outre, la plus grosse des boîtes contient une couche de colle animale recouvrant ce qui pourrait être un billet. La présence de cette colle, probablement composée à base de peau de lapin évoque la 
pratique consistant, à l'époque moderne, à noyer les reliques saintes trop petites dans de la colle animale. Or les fragments corporels, rognures d'ongle ou cheveux, la plupart faux, de l'Empereur déchu et emprisonné à Sainte-Hélène, ont circulé jusqu'à sa mort et audelà, alimentant un véritable trafic. La relique « laïque » faisant florès en ces décennies charnières des XVIII et $\mathrm{XIX}^{\mathrm{e}}$ siècles, rien n'interdit de penser que Mesnel aura pu insérer de tels restes impériaux dans la boîte contenant la colle.

À tous ces égards, et parce que la statue équestre d'Henri IV a cristallisé chez ses commanditaires et ses réalisateurs le besoin de laisser une trace, un témoignage de leurs interventions respectives, l'ensemble documentaire qui nous est livré évoque, toute mesure gardée, la pratique des capsules de temps. Il s'agit de boîtes, dans lesquelles sont enfermés des objets sélectionnés pour représenter une époque et une société. Cette pratique, attestée à partir des années 1930, est essentiellement le fait d'institutions nordaméricaines, qui constituent ces capsules à l'occasion d'un événement donné (exposition New York 1939), ou encore pour conserver l'essence des civilisations («crypte de la civilisation », scellée en 1936 par le président de l'université d'Ogglethorpe, au contenu voulu « encyclopédique »13. En détournant cet usage pour l'appliquer à de simples faits quotidiens, Andy Warhol, à partir des années 1960, réalisera à son tour de très nombreuses capsules de temps, en répertoriant et en indexant soigneusement le contenu.

Cette volonté de fixer l'événement en le documentant au moyen d'objets au pouvoir sémiotique fort est manifeste en 1818. Surtout, il apparaît clairement que les commanditaires ont voulu donner à l'édification de la statue un tour exceptionnel, et que manifeste la richesse des objets qui y sont enfermés, nouvelle pierre à l'édification du mythe henrissien.

La statue d'Henri IV au Pont-Neuf restaurée en 1818 est conçue comme un lieu de mémoire, réceptacle d'une histoire sur laquelle le nouveau régime veut porter une lumière qui lui soit favorable et qui surtout lui permette, après des années de guerres napoléoniennes, de faire figure, au plan national et international, d'autorité pacificatrice et fédératrice. C'est pour servir une propagande aux accents comparables que Napoléon III préside en 1867 à la fondation du musée des Archives et à l'installation des constitutions et des généalogies royales et impériales dans l'Armoire de fer, au cœur des Grands Dépôts des Archives impériales, à Paris. L'Armoire de fer, elle aussi lieu de mémoire puisqu'elle accueillit initialement les planches d'assignat et les constitutions de l'époque révolutionnaire, avant d'être transférée à l'hôtel de Soubise, affecté depuis 1808 à la conservation des Archives nationales, accueille aujourd'hui les boîtes retrouvées dans la statue du Pont-Neuf. Clin d'œil de l'histoire, le "trésor » constitué en 1818 passe d'un lieu de mémoire monarchique à un lieu de mémoire impérial, tout en conservant sa vocation initiale : résumer en l'incarnant un moment du destin politique d'un homme et d'une nation. 


\section{NOTES DE FIN}

1. Archives nationales Paris, AE/II/1291. Adresse du Comité «Henri IV » à l'Assemblée, 13 août 1792 : « <Les législateurs> nous ont chargés de remettre sur le bureau l'acte de fondation de cette statue qui a été trouvé dans les flancs du cheval, et de vous déclarer qu'ils ont changé le nom de la section de Henry IV en celui de la section du Pont-Neuf. »

2. Au sens de passerelle entre sémiologie et herméneutique, voir: Agamben, G. Signatura rerum. Paris : Vrin, 2009, p. 67.

3. Archives nationales Paris, AE/II/786.

4. Archives nationales Paris, AB/VIII/1. Je remercie Mme Denise Ogilvie, conservateur au Centre historique des Archives nationales, de m'avoir indiqué et transmis ces documents.

5. Rapport de l'architecte Le Père. Archives nationales Paris, F/13/1256/II/pièce 1.

6. Boîte $\mathrm{n}^{\circ} 1$ : plomb, âme de bois ; H. $36 \mathrm{~cm}$ x L. $25 \mathrm{~cm}$ x ép. $9,5 \mathrm{~cm}$.

7. Voir AE/I/15bis/1/2.

8. Boîte $n^{\circ} 2$ : plomb, âme de bois ; H. $36,5 \mathrm{~cm}$ x L. $24 \mathrm{~cm}$ x ép. $11 \mathrm{~cm}$.

9. Boîte $\mathrm{n}^{\circ} 3$ : plomb, âme de bois ; H. $38,5 \mathrm{~cm} \times$ L. $28 \mathrm{~cm}$ x ép. $6,5 \mathrm{~cm}$.

10. Boîte $\mathrm{n}^{\circ} 4$ : plomb, âme de bois ; H. $25,5 \mathrm{~cm}$ x L. $17,5 \mathrm{~cm}$ x ép. $6,5 \mathrm{~cm}$.

11. Voir Poulot, D. Musée, nation, patrimoine. 1789-1815. Paris, 1997, ill. 25 et légende.

12. Ce manuscrit est déposé aux Archives nationales, sous la cote AE/II/3868.

13. Voir Welfelé, O. «Appertiser la mémoire. Les capsules de temps. Un autre archivage ?», In Artières, Philippe, Arnaud, A. (éd.). Lieux d'archive. Paris, 2005, p. 187-195, spéc. p. 188-192.

\section{RÉSUMÉS}

La restauration récente de la statue d'Henri IV au Pont-Neuf a permis d'y découvrir sept boîtes enfermées là en 1818, au moment de son édification. Ces objets sont aujourd'hui conservés aux Archives nationales. La richesse et la diversité des pièces contenues dans ces boîtes sont à la mesure de l'importance qu'ont voulu donner les commanditaires de la statue au rétablissement de l'effigie royale sur le Pont-Neuf. La portée symbolique de cette réérection, effaçant l'œuvre révolutionnaire et consacrant le fondateur de la dynastie Bourbon, explique sans doute en partie le caractère exceptionnel de cet ensemble, mais pas seulement. L'article interroge la portée et la signification de cette insertion, tout en en détaillant le contenu.

\section{INDEX}

Mots-clés : ampliation, boîte, bourbons, charte, commémoration, consécration, effigie, étui, fondation, Hardouin de Péréfixe (Paul Philippe), imprimé, inauguration, médaille, mémoire, memorabilia, monarchie, monument, parchemin, place publique, procès-verbal, reliquaire, reliques, reliure, restauration, rouleau, souscripteur, souscription (comité de), statue, sully (Maximilien de Béthune dit), symbole, trésor, Voltaire (François Marie Arouet dit) 